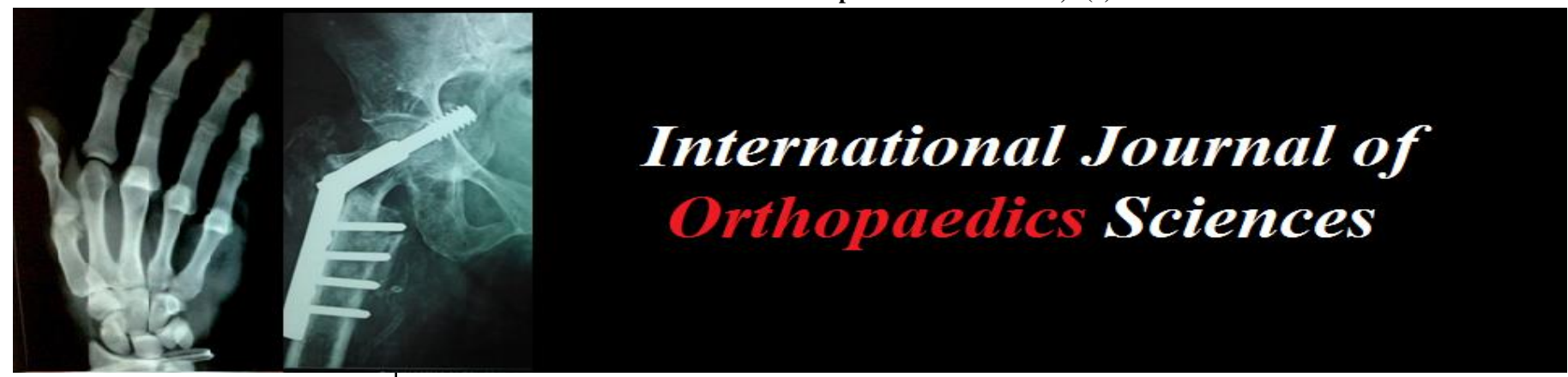

ISSN: $2395-1958$

IJOS 2018; 4(3): 189-193

(C) 2018 IJOS

www.orthopaper.com

Received: 05-05-2018

Accepted: 06-06-2018

Narendra Singh Kushwaha Department of Orthopaedic Surgery, King George Medical

University, Lucknow,

Uttar Pradesh, India

Sourabh Kumar Sinha

Department of Orthopaedic

Surgery, King George Medical

University, Lucknow,

Uttar Pradesh, India

\section{Aftab Alam}

Department of Orthopaedic

Surgery, King George Medical

University, Lucknow,

Uttar Pradesh, India

\section{Mayank Mahendra}

Department of Orthopaedic

Surgery, King George Medical

University, Lucknow,

Uttar Pradesh, India

\section{Vineet Sharma}

Department of Orthopaedic

Surgery, King George Medical

University, Lucknow,

Uttar Pradesh, India

\section{Correspondence}

Sourabh Kumar Sinha

Department of Orthopaedic

Surgery, King George Medical

University, Lucknow,

Uttar Pradesh, India

\section{Functional outcome of volar locked plate fixation in $\mathrm{AO}$ Type $B$ and $C$ fractures of distal end radius}

\author{
Narendra Singh Kushwaha, Sourabh Kumar Sinha, Aftab Alam, Mayank \\ Mahendra and Vineet Sharma
}

DOI: https://doi.org/10.22271/ortho.2018.v4.i3d.35

\begin{abstract}
Distal radius fractures are one of the most common orthopaedic injuries encountered in clinical practice. Owing to the increase in the number of road traffic accidents, these injuries are being seen with increasing frequency in younger people. Several treatment modalities have been described which includes closed reduction and application of plaster cast, bridging external fixation and open reduction and internal fixation (ORIF) by dorsal or volar conventional or locked plates. The aim of the present study was to assess the functional outcome of AO type B (partial articular) and type C (complete articular) fractures of distal radius among the patients undergoing ORIF by volar locked plate. A prospective study was conducted where patients of age more than 18 years of either sex having intraarticular fractures of the distal radius were enrolled in the study. Standard Henry's volar approach was used and a standard $3.5 \mathrm{~mm}$ volar locking plate was applied over the volar aspect of radius. 53 patients were included in the study. The mean age of patients was 48.74 years. At the end of one year follow up, 12 patients (22.6\%) had no pain, 33 had mild, occasional pain, 8 patients (15\%) had moderate but tolerable pain. As far as functional status is concerned, most $(91 \%)$ returned to their previous routine activities. Locked volar fixed angle plate fixation is a relatively safe and effective option for the management of partial articular (AO Type B) and completely articular fractures (AO Type C).
\end{abstract}

Keywords: Distal end radius, intraarticular fracture, locking compression plate, trauma

\section{Introduction}

Distal radius fractures are one of the most common orthopaedic injuries encountered in clinical practice, accounting for nearly $17 \%$ of all the fractures ${ }^{[1]}$. They are more often seen in old osteoporotic patients due to trivial trauma like fall ${ }^{[2]}$. Owing to the increase in the number of road traffic accidents, these injuries are being seen with increasing frequency in younger people as well ${ }^{[3]}$.

Several treatment modalities have been described which includes closed reduction and application of plaster cast, bridging external fixation and open reduction and internal fixation (ORIF) by dorsal or volar conventional or locked plates ${ }^{[4]}$. The drawbacks of cast immobilization and external fixation remains inadequate reduction or loss of reduction and stiffness due to prolonged immobilization ${ }^{[5,6]}$. In order to avert these problems, open anatomical reduction and absolute stability by volar locking plates have come in vogue and has become the treatment modality of choice in the last few years ${ }^{[6-8]}$. It allows immediate mobilization and hence, rapid recovery. Being locked plates, they act on the principles of internal fixator. So, even monocortical screws can suffice ${ }^{[9,10]}$. Application of the plate on the volar surface is better because- 1 . The flexor tendons are not as close to the bone as the extensor tendons, and hence tendon related complications are less common, 2. There is a layer of pronator quadratus muscle which inhibits direct contact of the tendons with the plate, 3 . The volar surface is more flatter making plate application easier ${ }^{[11,12]}$. The screws lock with the plate holes, which provide angular stability, prevents backout of screws and plate, and thus minimizes the chances of secondary displacement following fracture reduction and fixation ${ }^{[8-10]}$. The aim of the present study was to assess the functional outcome of AO type B (partial articular) and type $\mathrm{C}$ (complete articular) fractures of distal radius among the patients undergoing ORIF by volar locked plate. 


\section{Material and methods}

A prospective study was conducted where patients of age more than 18 years of either sex having intraarticular fractures of the distal radius were enrolled in the study. Patients with Gustilo Anderson Grade 2 or 3, injury duration more than 7 days, associated neurovascular deficit, other fractures of the ipsilateral limb, polytrauma patients and those not giving informed consent were excluded from the study. Standard AP and lateral views of wrist with forearm were taken. Fractures were classified on the basis of AO classification. Demographic and clinical data of patients were recorded. Patients were operated after preanesthetic clearance was obtained. Brachial plexus block or general anesthesia was used. Tourniquet was used in all the cases. Standard Henry's volar approach was used where surgical plane was created between flexor carpi radialis tendon and median nerve. Pronator quadratus was found ruptured in many cases. However, we tried our best to delineate it properly, which was reflected medially. In those cases where radial styloid was fractured and needed to be fixed separately, we adopted modified Henry's approach by going in between FCR and Radial artery. The articular reduction was achieved first followed by the reduction of the reconstructed epiphysiometaphyseal fragment to the rest of the radius. Reduction was achieved by traction and standard reduction manoeuvres. Provisional fixation was done by the help of Kwires. Thereafter, a standard, $3.5 \mathrm{~mm}$ volar locking plate was applied over the volar aspect of radius. A standard nonlocking screw was passed through the distal oval combi-hole. The plate was slid proximally or distally depending on the fracture level. Intra-operative fluoroscopy was used to ascertain the quality of reduction in both anteroposterior and lateral views. Then locking screws were applied. The nonlocking screw of the combi-hole was removed and a locking screw was applied. Due precautions were taken to ensure that the screw sizes were appropriate so as to avoid the problems associated with extensor tendons like tenosynovitis and rupture. Pronator quadratus was repaired and the wound closed. A dorsal below elbow POP slab was used for 10 days, when stitches were removed. Supervised physiotherapy was started thereafter. The patients were specially instructed not to perform any heavy work with the operated upper limb.

Patients were followed up at 6 weeks, 3, 6 and 12 months. Complete clinical and radiological examination of the affected limb was done. The wrist was examined for presence of tenderness and deformity. The range of motion of the wrist was measured in two planes with the help of a goniometer and compared with opposite wrist- (a) Flexion-Extension (b) Adduction-Abduction. Supination and pronation of the forearm was also measured. Pain intensity and functional status were observed and grip strength was measured by the help of dynamometer. The functional outcome score was measured on the criteria of modified Mayo wrist score at last follow up and compared with that of unaffected side.

Radiologically, radial inclination, radial length, volar tilt and ulnar variance were recorded in the pre-operative, immediate post-operative, and at 3,6,12 months follow up X-rays [Figure 1 and Figure 2].

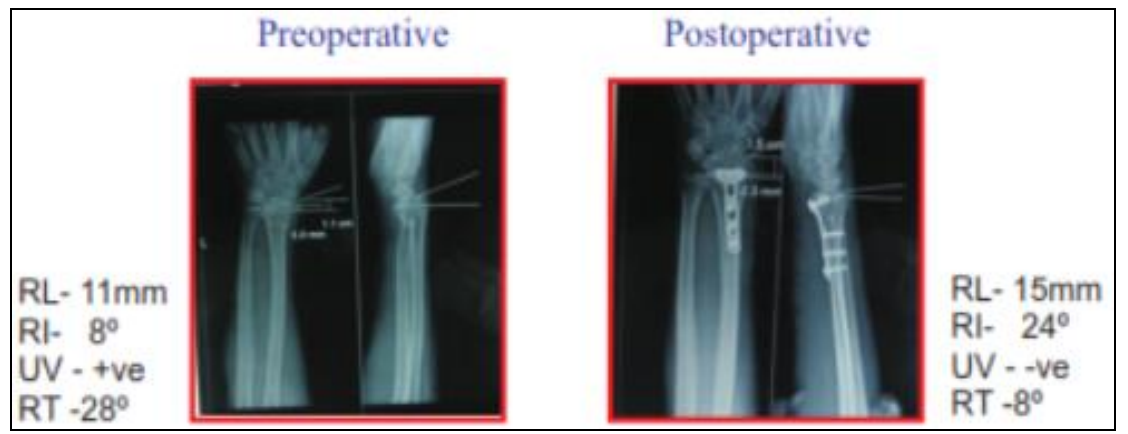

Fig 1: Pre and post operative $X$ ray of wrist showing various parameters.

$\mathrm{RL}=$ Radial length

$\mathrm{RI}=$ Radial inclination

$\mathrm{UV}=\mathrm{Ulnar}$ variance

RT=Radial tilt

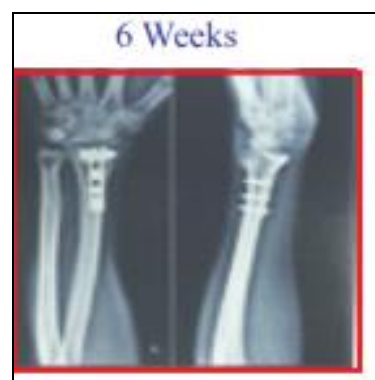

$\mathrm{RL}-15 \mathrm{~mm}$

RI- $24^{\circ}$

UV - -ve

RT $-5^{\circ}$
3 Months

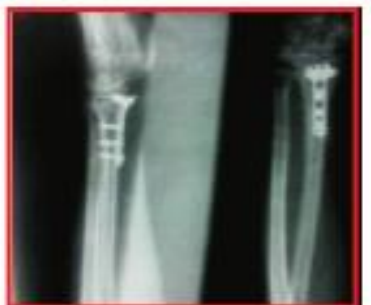

$\mathrm{RL}-15 \mathrm{~mm}$

RI- $26^{\circ}$

UV - -ve

RT $-4^{\circ}$

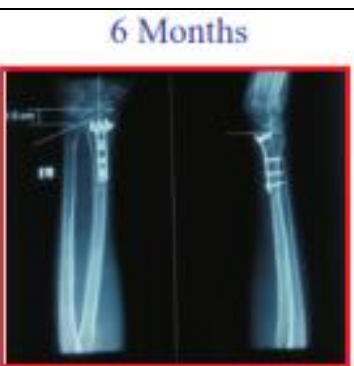

$\mathrm{RL}-15 \mathrm{~mm}$

RI- $26^{\circ}$

UV - -ve

RT $-0^{\circ}$

Fig 2: Follow up $\mathrm{X}$ ray of wrist at 6 weeks, 3months and 6 months showing various parameters.

$\mathrm{RL}=$ Radial length

$\mathrm{RI}=$ Radial inclination

$\mathrm{UV}=\mathrm{Ulnar}$ variance

$\mathrm{RT}=$ Radial tilt 


\section{Observation and Results}

A total of 53 patients were included in the study. There were 38 males and 15 females. The mean age of patients was 48.74 years. All the patients had completed a minimum follow up of 1 year (mean follow up=1.6 years). Mode of trauma was either trivial fall or road traffic accident. Most of the patients were elderly males. Dominant hand was involved in $78 \%$ of the cases. Fractures were classified on the basis of $\mathrm{AO}$ classification. The clinical profile of patients is shown in table 1. Mean range of motion of the affected wrist as a percentage of the motion on unaffected side was $81 \%$ for flexion, $82 \%$ for extension, $78.5 \%$ for adduction (ulnar deviation), $68 \%$ for abduction(radial deviation), $89 \%$ for supination and $88 \%$ for pronation (Table 2). Mean grip strength was $81 \%$ of that of unaffected side. At the end of one year follow up, 12 patients $(22.6 \%)$ had no pain, 33 had mild, occasional pain, 8 patients $(15 \%)$ had moderate but tolerable pain. As far as functional status is concerned, most $(91 \%)$ returned to their previous routine activities. There were 5 patients $(9 \%)$ who had some difficulty in performing their professional work, 3 due to restricted range of motion and 2 due to extensor tendon rupture. On the basis of modified Mayo score, the results were excellent in $67 \%$ cases, good in $24 \%$, satisfactory in $6 \%$ and failure in $2 \%$ cases (table 3 ).

Radiographic parameters were as mentioned in the table 4. We also looked into any possible association between the difference between the normal and affected sides of mean average range of motion, grip strength and the radiological parameters. We found a significant association between range of motion and grip strength. There was some collapse of the fractured fragments in the follow up periods leading to somewhat lesser radial inclination and radial length. Out of 53 patients, post-operative infection was seen in one case which was managed by re-exploration and debridement. The patient had Gustilo-Anderson Grade 1 open fracture due to road traffic accident who had presented to us within 2 hours. The patient had no signs of infection since then. Among the other complications, there were loss of reduction leading to malunion $(n=4)$, median nerve compression $(n=3)$, reflex sympathetic dystrophy $(n=4)$ and tendon related complications $(n=2)$.

\section{Discussion}

Volar locking plate has become the treatment of choice in the last decade for the treatment of intra-articular distal radius fractures. It is quite helpful in restoring the articular anatomy and preventing its collapse and hence earlier recovery and good functional outcome ${ }^{[7,15]}$.

The construct is so stable that one does not need to immobilize the wrist. However, in our study, we applied below elbow slab for faster healing of the skin incision, which was removed after 10 days. As with all articular fractures, mobilization of the wrist also facilitates good joint lubrication and prevents stiffness ${ }^{[16]}$.

Our results in terms of regaining the range of motion and radiological parameters correlates well with other studies $[9,11$, $18]$

Tendon related complications in our study are much less (3.8\%) compared to the previous studies. This may be due to 2 reasons- (i) Appropriate size of screws were used, ensuring that the screws did not protrude over the dorsal aspect, (ii) We tried not to cross the watershed line on the volar aspect during plate application. Both these factors are important for preventing extensor and flexor tendon impingement respectively as has been highlighted in other studies ${ }^{[19]}$. The patients were advised for tendolysis and repair but did not give consent.

Median nerve compression was seen in 3 cases where pain, tingling and numbness was complained by the patient when specially asked for in the immediate post-operative period. No motor weakness was evident on clinical examination. But, the symptoms were transient and not present during subsequent follow-ups. No patient required carpel tunnel release. The cause of transient neuropathy may be post-operative oedema or tight plaster slab. Ho et al. ${ }^{[20]}$ in a retrospective study of 282 volar plating cases found that post-operative hand numbness developed in 24 cases, out of which 9 had carpal tunnel syndrome i.e.3.2\% (9/282). This is similar to the the study of Xavier et al. ${ }^{[21]}$ and Arora et al. ${ }^{[2]}$ where features of carpel tunnel syndrome was seen in $3 \%$ of the cases.

Reflex sympathetic dystrophy(RSD) was relatively more common(7.5\%) in our study as compared to the previous reported studies ${ }^{[10,21]}$ Out of the 4 patients, 3 were in the age group $>70$ years. Probably, osteoporosis and psychiatric disturbances might have played a role. Whether it has got anything to do with the surgical intervention, is still uncertain. Few studies have shown that the incidence of RSD after distal radius fracture is not altered by operative intervention. Some studies have also demonstrated role of Vitamin $\mathrm{C}$ in the prevention of RSD ${ }^{[22,23]}$.

In one of the 4 cases where fracture collapse happened, we had cut through of the screw leading to penetration into the joint cavity. In the immediate post-op X-rays, the screws were abutting the articular margin. The probable cause of screw cut through was the collapse of the fracture fragments. The patient had plate removal at 1 year and 9 months of follow up. In the rest, there was decreased radial length and dorsal angulation. Out of these patients, 3 were of AO Type C3 and 1 of AO Type C2.

We were unable to find any definite association between the radiological indices at final follow up and clinical outcome. The same has been noted by Anzarut et al. ${ }^{[24]}$ and Barton et al. ${ }^{[25]}$ However, Xavier et al. ${ }^{[21]}$ have shown radial length to be an important determinant of difference in extension and grip strength between the fractured and non-fractured limbs. Trumble et al. ${ }^{[26]}$ in a study of management of distal radius fractures by K-wires have shown that radial length restoration was the most important factor determining the functional outcome. In a biomechanical study, Tang et al. ${ }^{[27]}$ has shown that significant changes occur in the moment of forces of the tendons by loss of radial length.

The functional oucome of AO type B fractures were better than AO type $\mathrm{C}$ fractures. But, no definite association could be found within the groups. We feel that restoration of articular geometry is more important factor which decides the functional outcome, rather than the type of fracture at the time of initial presentation.

Age was a significant factor determining the functional as well as radiological outcome. As already pointed out, the collapse of the reconstructed part of radius leading to decrease in radial length and ulnar variance at the time of final follow up was seen more in old (60yrs age) patients, probably due to osteoporosis. Also the range of motion and grip strength was significantly lower in these patients.

Dorsal plate has got advantage in the form of buttressing the distal fragments which in most of the cases is dorsally displaced. Volar plates, on the other hand have got numerous advantages-lower incidence of tendon related complications, easier application and preservation of vascular supply of dorsal fragments. As the plates are locking plates, plate-screw 
construct becomes an integrated one and axial forces do not cause screw toggling and back-out. Also, it doesn't require friction between the plate and bone for stability and hence periosteal blood supply is better preserved. Wei et al. [28] compared the dorsal and volar plating in distal radius fractures and found that volar fixation was associated with significant increase in neuropathy and carpel tunnel syndrome and a reduced incidence of tendon irritation compared to dorsal group.

External fixation in cases of distal radius fractures relies on ligamentotaxis. They can also be associated with complications like malreduction, finger and wrist stiffness, nerve injury, RSD, and those related to pin tract like infections and loosening. Recent meta-analysis by Walenkamp et al. ${ }^{[29]}$ have shown that distal radius fractures treated with a volar locking plate had a better functional outcome than (augmented) external fixation at 3,6 and 12 months.

Our study had few limitations. Firstly, it was a short term study. So, no definite conclusions could be drawn as regards to the development of osteoarthritis. Secondly, there was no control group to see if this method of treatment is better than other modalities like K-wire fixation or external fixator application or dorsal plating. Thirdly, our sample size was small to find out if there is any association between radiological parameters and clinical outcome.

\section{Conclusion}

On the basis of our study and comparing our results with others, we conclude that locked volar fixed angle plate fixation is a relatively safe and effective option for the management of partial articular (AO Type B) and completely articular fractures (AO Type C). Due care should be taken to ensure anatomical reduction, selecting the appropriate screw sizes, avoiding crossing the watershed line and proper physiotherapy to get optimum results. In people above 70 years of age and those with severe osteoporosis, it should be used with caution. Volar plating has got good functional and radiological outcome and minimal complications.

Table 1: Clinical profile of the patients

\begin{tabular}{|c|c|c|}
\hline \multirow{2}{*}{ Age } & $<60$ years & 36 \\
\cline { 2 - 3 } & $>60$ years & 17 \\
\hline Mean age at presentation & 48.74yrs \\
\hline \multirow{2}{*}{ Sex } & Males & 38 \\
\cline { 2 - 3 } & Females & 15 \\
\hline \multirow{4}{*}{ Mode of injury } & Fall & 29 \\
\cline { 2 - 3 } & RTA & 23 \\
\cline { 2 - 3 } & Physical Assault & 1 \\
\hline \multirow{3}{*}{ Type of fracture (AO Classification) } & B1 & 4 \\
\cline { 2 - 3 } & B2 & 8 \\
\cline { 2 - 3 } & B3 & 5 \\
\cline { 2 - 3 } & C1 & 8 \\
\cline { 2 - 3 } & C2 & 12 \\
\cline { 2 - 3 } & C3 & 16 \\
\hline
\end{tabular}

Table 3: Modified Mayo score ${ }^{[13]}$

\begin{tabular}{|c|c|c|c|}
\hline \multicolumn{2}{|c|}{ Pain Intensity } & \multicolumn{2}{|c|}{ Functional Status } \\
\hline \multicolumn{2}{|c|}{ No Pain -25} & \multicolumn{2}{|c|}{ Regular Job -25} \\
\hline \multicolumn{2}{|c|}{ Mild, Occasional -20} & \multicolumn{2}{|c|}{ Restricted Employment -20} \\
\hline \multicolumn{2}{|c|}{ Moderate, Tolerable -15} & \multicolumn{2}{|c|}{ Able to work, but unemployed -15} \\
\hline \multicolumn{2}{|c|}{ Severe, Intolerable - 0} & \multicolumn{2}{|c|}{ Unable to work due to pain -0} \\
\hline \multicolumn{2}{|c|}{ Range of Movement (\% of normal side) } & \multicolumn{2}{|c|}{ Grip Strength (\% of normal side) } \\
\hline $100 \%$ & -25 & $90-100 \%$ & -25 \\
\hline $75-99 \%$ & -20 & $75-89 \%$ & -15 \\
\hline $50-74 \%$ & -15 & $50-74 \%$ & -10 \\
\hline $25-49 \%$ & -10 & $25-49 \%$ & -5 \\
\hline $0-24 \%$ & -5 & $0-24 \%$ & -0 \\
\hline
\end{tabular}

Interpreting the Mayo Wrist Score

\begin{tabular}{|c|c|}
\hline $91-100$ & Excellent \\
\hline $81-90$ & Good \\
\hline $61-80$ & Satisfactory \\
\hline Below 60 & Poor \\
\hline
\end{tabular}

Table 2: Range of movement

\begin{tabular}{|c|c|c|c|}
\hline Types of movement & Unaffected side (ROM) mean & Affected side (ROM) mean \pm S.D. & Percentage of affected side \\
\hline Flexion & 73.96 & $59.81 \pm 6.50$ & 80.87 \\
\hline Extension & 68.77 & $56.60 \pm 5.95$ & 82.30 \\
\hline Abduction & 19.53 & $13.25 \pm 4.03$ & 67.84 \\
\hline Adduction & 30.38 & $23.87 \pm 4.87$ & 78.57 \\
\hline Supination & 88.87 & $79.06 \pm 5.89$ & 88.96 \\
\hline Pronation & 81.89 & $72.17 \pm 5.5$ & 88.13 \\
\hline
\end{tabular}


Table 4: Radiological parameters of the patients

\begin{tabular}{|l|c|c|c|c|c|}
\hline & Radiographic parameters & Normal values ${ }^{[14]}$ & Immediatepost-operative & Follow up at 1 year & Contra-lateral side \\
\hline 1. & Radial inclination & $13-30^{0}\left(23^{0}\right)$ & 19.23 & 18.72 & 21.30 \\
\hline 2. & Radial length & $11-12 \mathrm{~mm}$ & 9.88 & 9.49 & 10.70 \\
\hline 3. & Volar tilt & $0-28^{0}\left(11^{0}\right)$ & 7.12 & 7.08 & 10.68 \\
\hline 4. & Ulnar variance & $2 \mathrm{~mm}$ & 1.20 & 1.08 & 1.53 \\
\hline
\end{tabular}

\section{References}

1. Singer BR, McLauchlan GJ, Robinson CM, Christie J. Epidemiology of fractures in 15,000 adults: the influence of age and gender. J Bone Joint Surg (Br). 1998; 80(2):243-248.

2. Arora R, Gabl M, Gschwentner M, Deml C, Krappinger D, Lutz M. A comparative study of clinical and radiologic outcomes of unstable colles type distal radius fractures in patients older than 70 years: nonoperative treatment versus volar locking plating. J Orthop Trauma. 2009; 23(4):237-42.

3. Staa TPV, Dennison EM, Leufkens HGM, Cooper C. Epidemiology of Fractures in England and Wales. Bone. 2001; 29(6):517-522

4. McQueen MM, Hajducka C, Court-Brown CM. Redisplaced unstable fractures of the distal radius: a prospective randomised comparison of four methods of treatment. J Bone Joint Surg Br. 1996; 78(3):404-9.

5. Wierer I, Pospisil M, Franz J. Treatment of Colles' fractures in elderly patients. (Analysis of 356 patients treated in 1973-1977). Acta Univ Carol. 1985; 31:165172.

6. Douthit JD. Volar Plating of Dorsally Comminuted Fractures of the Distal Radius: A 6-Year Study. Am J Orthop. 2005; XXXIV:140-147.

7. Martineau PA, Berry GK, Harvey EJ. Plating for distal radius fractures. Orthopedic Clinics of North America. 2007; 38(2):193-201.

8. Chung KC, Watt AJ, Kotsis SV. Treatment of unstable distal radial fractures with the volar locking plating system. J Bone Joint Surg Am. 2006; 88:2687-2694.

9. Wong KK. Volar fixation of dorsally displaced distal radial fracture using locking compression plate. J Orthop Surg (Hong Kong). 2005; 13(2):153-7.

10. Arora R, Lutz M, Hennerbichler A, Krappinger D, Espen $\mathrm{D}$, Gabl M. Complications following internal fixation of unstable distal radius fracture with a palmar lockingplate. J Orthop Trauma. 2007; 21(5):316-22.

11. Gogna P, Selhi HS, Singla R. Dorsally Comminuted Fractures of the Distal End of the Radius: Osteosynthesis with Volar Fixed Angle Locking Plates. ISRN Orthopedics, 2013, 131757.

12. Sharma RL, Sharma S, Pandey BK, Manandhar RR, Lakhey S, Rijal KP. Osteosynthesis of unstable fractures of distal radius with volar locking plate. Nepal Orthopaedic Association Journal (NOAJ). 2011; 2(1):2734.

13. Souer JS, Lozano-Calderon SA, Ring D. Predictors of wrist function and health status after operative treatment of fractures of the distal radius. J Hand Surg Am. 2008; 33(2):157-163.

14. Loredo RA, Sorge DG, Garcia G. Radiographic evaluation of the wrist: a vanishing art. Semin Roentgenol. 2005; 40(3):248-289.

15. Orbay JL, Fernandez DL. Volar fixation for dorsally displaced fractures of thedistal radius: a preliminary report. J Hand Surg Am. 2002; 27(2):205-15.

16. Grimsby O, Rivard J. Exercise rehabilitation of the elbow and wrist. Science, Theory and Clinical Application in Orthopaedic Manual Physical Therapy: Scientific Therapeutic Exercise Progressions (STEP): The Neck and Upper Extremity. San Diego: Ola Grimsby Institute, 2009.

17. Minegishi H, Dohi O, An S, Sato H. Treatment of unstable distal radius fractures with the volar locking plate. Upsala Journal of Medical Sciences. 2011; 116(4):280-284.

18. Orbay JL, Touhami A. Current concepts in volar fixedangle fixation of unstable distal radius fractures. Clin Orthop Relat Res. 2006; 445:58-67.

19. Ho AWH, Ho ST, Koo SC, Wong KH. Hand numbness and carpal tunnel syndrome after volar plating of distal radius fracture. Hand (New York, NY). 2011; 6(1):34-38.

20. Xavier CRM, Molin DCD, Santos RMM, Santos RDT, Neto JCF. Surgical treatment of distal radius fractures with a volar locked plate: correlation of clinical and radiographic results. Rev Bras Ortop. 2011; 46(5):50513.

21. Zollinger PE. No Higher Risk of CRPS After External Fixation of Distal Radial Fractures - Subgroup Analysis Under Randomised Vitamin C Prophylaxis. The Open Orthopaedics Journal. 2010; 4:71-75.

22. Frölke JP. Can vitamin C prevent complex regional pain syndrome in patients with wrist fractures? J Bone Joint Surg Am. 2007; 89(11):2550-1. Author reply 2551-2.

23. Anzarut A. Radiologic and patient-reported functional outcomes in an elderly cohort with conservatively treated distal radius fractures. J Hand Surg Am. 2004; 29(6):1121-7.

24. Barton T, Chambers C, Bannister G. A comparison between subjective outcome score and moderate radial shortening following a fractured distal radius in patients of mean age 69 years. J Hand Surg Eur. 2007; 32(2):1659.

25. Trumble TE, Wagner W, Hanel DP, Vedder NB, Gilbert M. Intrafocal (Kapandji) pinning of distal radius fractures with and without external fixation. J Hand Surg Am. 1998; 23(3):381-94.

26. Tang JB, Ryu J, Kish V, Wearden S. Effect of radial shortening on muscle length and moment arms of the wrist flexors and extensors. J Orthop Res. 1997; 15(3):324-30.

27. Wei J, Yang TB, Lui W, Qin JJB, Kong FJ. Complications following dorsal versus volar plate fixation of distal radius fracture: A meta-analysis. Journal of International Medical Research. 2013; 41(2):265-275.

28. Walenkamp MMJ, Bentohami A, Beerekamp MSH et al. Functional outcome in patients with unstable distal radius fractures, volar locking plate versus external fixation: a meta-analysis. Strategies in Trauma and Limb Reconstruction. 2013; 8(2):67-75. 